Original Papers

\title{
Sodium Dodecyl Sulfate-Linear Polyacrylamide-Bonded Capillary Electrophoresis for the Molecular Weight Determination of Proteins
}

\author{
Manabu NaKatani*, Akimasa ShibUKawa** and Terumichi Nakagawa** \\ *Pharmaceutical Research Department, Nippon Boehringer Ingelheim Co., Ltd., \\ Yato Kawanishi, Hyogo 666-01, Japan \\ **Faculty of Pharmaceutical Sciences, Kyoto University, Sakyo, Kyoto 606-01, Japan
}

\begin{abstract}
Sodium dodecyl sulfate (SDS)-linear polyacrylamide-bonded capillary electrophoresis has been developed for the separation and molecular weight determination of proteins. Vinyl groups were introduced to silanol groups on the inner wall of fused silica capillaries by a Grignard reaction, followed by reaction of the vinyl group with acrylamide, resulted in a sieving medium of linear polyacrylamide attached through hydrolytically stable Si-C linkages. The durability of the developed capillary were improved as compared with the SDS-linear polyacrylamide-filled capillary using a conventional fused silica capillary. An excellent linear relationship existed between the mobility and the logarithm of the molecular weight of proteins $\left(r^{2}>0.998\right)$. The relative standard deviation of migration times was below $1.0 \%(n=10)$.
\end{abstract}

Sodium dodecyl sulfate-polyacrylamide gel electrophoresis has often been used for the separation and molecular weight determination of proteins. ${ }^{1}$ However, it has limitations of time consumption, tedious detection and difficulty in quantification. In contrast, SDScapillary gel electrophoresis (SDS-CGE) has advantages over slab gel electrophoresis; for example, a high intensity of electric field can be applied and the oncolumn detection instead of staining can be employed, thus enabling high speed separation and real time detection.

SDS-CGE has been achieved using cross-linked polyacrylamide gels $^{2-3}$, linear polyacrylamide solutions $^{4-5,19}$ and other polymers. ${ }^{6-7}$ However, the crosslinked polyacrylamide gels are not very successful because gel shrinkage during polymerization often produces some cracks in the gel inside the capillary. ${ }^{8}$ Another problem is concerned with electroosmotic flow in the capillary: the electroosmotic pressure due to zeta potential on the untreated silica surface causes the gel to be gradually extruded out of the capillary. To avoid these troubles, various procedures have been developed for the preparation of immobilized ge $^{9-14}$ by chemical bondings to the silica surface through the siloxane linkages. However, it is well-known that siloxane linkages are prone to hydrolysis under alkaline conditions. ${ }^{15}$

This report describes the preparation of the linear polyacrylamide gel-bonded capillary by $\mathrm{Si}-\mathrm{C}$ linkages, which resists hydrolysis even in alkaline condition. The capillary was used for the separation and molecular weight determination of SDS-proteins, giving the higher efficiency and stability than those so far reported.

\section{Experimental}

\section{Reagents and materials}

Acrylamide, $\quad N, N, N^{\prime}, N^{\prime}$-tetramethylethylenediamine (TEMED), ammonium persulfate (APS) of electrophoretic grade, thionyl chloride, tetrahydrofuran (THF), sodium dodecyl sulfate (SDS), Orange G and 2mercaptoethanol of reagent grade were obtained from Wako (Osaka, Japan). Vinylmagnesium bromide (1 M solution in THF) was purchased from Aldrich Chemical Co. (Milwaukee, WI, USA). The buffer solution for electrophoresis consisted of $49 \mathrm{mM}$ Tris, $384 \mathrm{mM}$ glycine and $0.1 \% \mathrm{w} / \mathrm{v}$ SDS. Standard proteins were obtained from Sigma (St. Louis, MO, USA).

\section{Apparatus}

A capillary electrophoresis instrument, CE-800 (JASCO, Tokyo, Japan), was used with a fused silica capillary (GL Sciences, Tokyo, Japan) of $75 \mu \mathrm{m}$ i.d., $375 \mu \mathrm{m}$ o.d. $\times 50 \mathrm{~cm}$ (length to detector: $30 \mathrm{~cm}$ ). Capillary electrophoresis was achieved at room temperature without temperature control.

Preparation of the linear polyacrylamide-bonded capillaries through Si-C linkages

A detection window was opened by burning off about $2 \mathrm{~mm}$ length of polyimide coating on a fused silica 


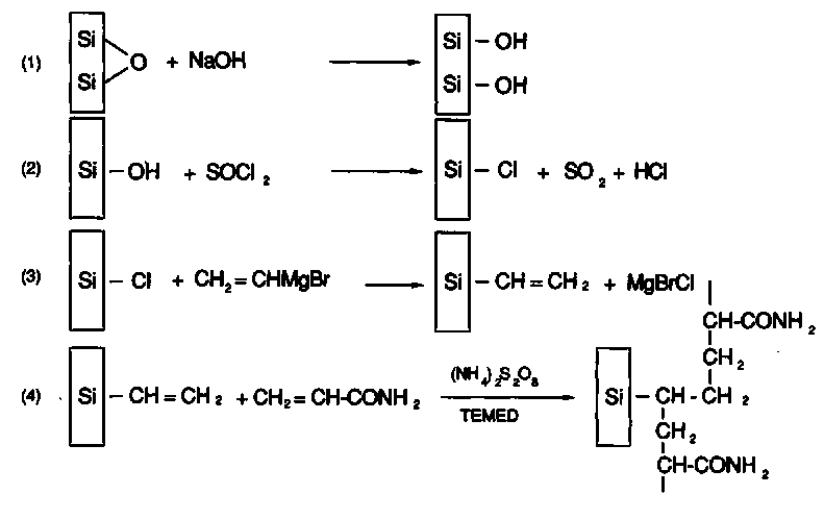

Fig. 1 Reaction scheme for bonding to linear polyacrylamide via $\mathrm{Si}-\mathrm{C}$ linkages.

capillary at an appropriate position. The capillary was treated by four step reactions shown in Fig. 1, which are basically the same as that reported by Novotny et $a .^{16}$, but the procedure was improved as follows.

The capillary was first treated with $1 \mathrm{M} \mathrm{NaOH}$ at room temperature for $1 \mathrm{~h}$, rinsed with distilled water, and dried at $110^{\circ} \mathrm{C}$ by streaming nitrogen gas for $6 \mathrm{~h}$. Thionyl chloride was passed through the dried capillary for several minutes using a suction pump. The capillary was sealed at both ends and kept at $70^{\circ} \mathrm{C}$ for $6 \mathrm{~h}$. After reaction the seal was opened, and $0.25 \mathrm{M}$ vinylmagnesium bromide solution in THF was introduced into the capillary by suction. The capillary was sealed again and kept at $70^{\circ} \mathrm{C}$ for $6 \mathrm{~h}$ to complete the Grignard reaction. After reaction, the seal was opened and the capillary was rinsed with THF for several minutes, then with distilled water. An aqueous solution containing $3 \% \mathrm{w} / \mathrm{v}$ to 9\%w/v acrylamide, $49 \mathrm{mM}$ Tris, $384 \mathrm{mM}$ glycine and $0.1 \% \mathrm{w} / \mathrm{v}$ SDS was degassed in an ultrasonic bath. Forty microliters of $10 \% \mathrm{v} / \mathrm{v}$ TEMED and $10 \mu \mathrm{l}$ of $10 \% \mathrm{w} / \mathrm{v}$ APS were added to $5 \mathrm{ml}$ of the degassed solution, mixed thoroughly, and introduced into the capillary. After polymerization at $28 \pm 2^{\circ} \mathrm{C}$ for $1 \mathrm{~h}$, the capillaries were conditioned at $-100 \mathrm{~V} / \mathrm{cm}$ for $30 \mathrm{~min}$.

\section{Preparation of the linear polyacrylamide-filled capillary}

A detection window on a capillary was opened using the above mentioned procedure. The solution containing $5 \% \mathrm{w} / \mathrm{v}$ acrylamide, $49 \mathrm{mM}$ Tris, $384 \mathrm{mM}$ glycine and $0.1 \% \mathrm{w} / \mathrm{v}$ SDS was degassed in an ultrasonic bath. Forty microliters of $10 \% \mathrm{v} / \mathrm{v}$ TEMED and $10 \mu \mathrm{l}$ of $10 \% \mathrm{w} / \mathrm{v}$ APS were added to $5 \mathrm{ml}$ of the degassed solution, mixed thoroughly, and introduced into the capillary. After polymerization at $28 \pm 2^{\circ} \mathrm{C}$ for $1 \mathrm{~h}$, the capillaries were conditioned at $-100 \mathrm{~V} / \mathrm{cm}$ for $30 \mathrm{~min}$.

\section{Protein samples for SDS-electrophoresis}

A mixture of standard proteins was dissolved in a buffer solution containing $4.9 \mathrm{mM}$ Tris, $38.4 \mathrm{mM}$ glycine, $2 \% \mathrm{w} / \mathrm{v}$ SDS and $1 \% \mathrm{v} / \mathrm{v}$ 2-mercaptoethanol. The sample solution was incubated at $80^{\circ} \mathrm{C}$ for $15 \mathrm{~min}$ in a water bath and then submitted to analysis.
ANALYTICAL SCIENCES FEBRUARY 1994, VOL. 10

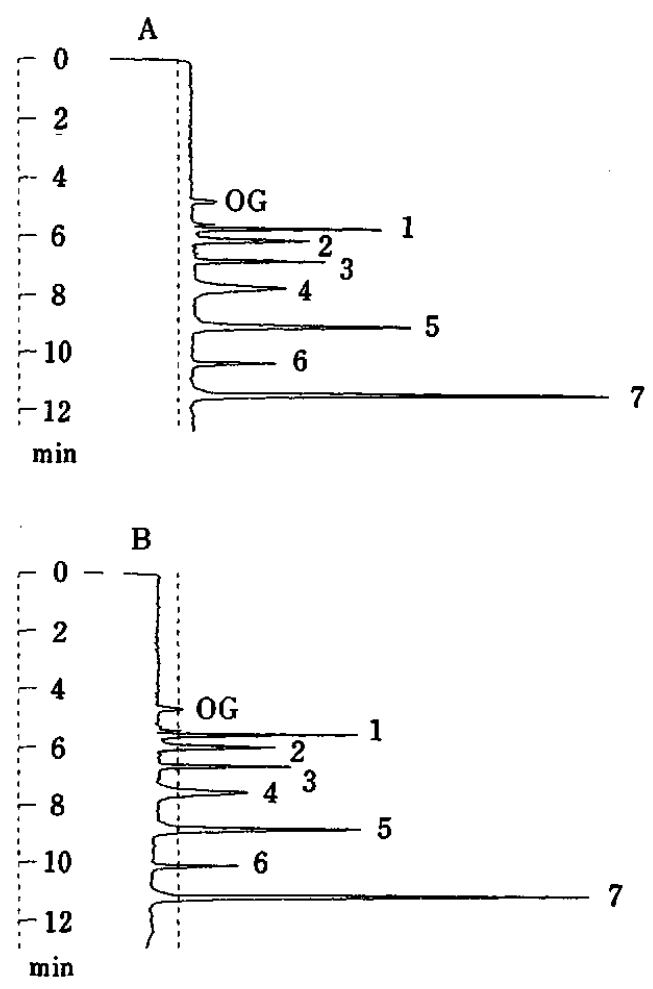

Fig. 2 Electropherograms of standard proteins on the $5 \%$ $\mathrm{w} / \mathrm{v}$ linear polyacrylamide-bonded capillary. The peak number specifies the protein shown in Table 1. Capillary, $75 \mu \mathrm{m}$ i.d. $\times 50 \mathrm{~cm}$ ( $30 \mathrm{~cm}$ to detector), running buffer, $49 \mathrm{mM}$ Tris, $384 \mathrm{mM}$ glycine, $0.1 \% \mathrm{w} / \mathrm{v}$ SDS $\mathrm{pH}=8.7$; separation conditions, $-20 \mathrm{kV} 23 \mu \mathrm{A}$; injection, $-5 \mathrm{kV} 5 \mu \mathrm{A} 10 \mathrm{~s}$; detection, UV/280 nm; (A) 1st run, (B) 10th run.

\section{Results and Discussion}

Figure 2 shows the electropherograms of standard proteins separated in the $5 \%$ linear polyacrylamidebonded capillary through Si-C linkages, where the intensity of the applied electric field was $-400 \mathrm{~V} / \mathrm{cm}$, and the detection was achieved at $U V / 280 \mathrm{~nm}$. The proteins with molecular weight ranging from 14400 to 116000 were completely separated within $12 \mathrm{~min}$ with high efficiency; for example, the plate number for peak 6 (phosphorylase $b$ ) in Fig. 2A is approximately 100000 . The peak marked with OG corresponds to the internal standard (Orange $\mathrm{G}$ ). There is no difference in the separation efficiency between the 1st run (Fig. 2A) and the 10th run (Fig. 2B). Figure 3 shows the electropherograms of standard proteins measured using the surface untreated capillary under the same separation conditions as in Fig. 2, indicating rapid decrease in the separation efficiency by the repeated use.

Table 1 shows the statistical data for the run-to-run reproducibility of the migration times and the relative migration times in the 5\% linear polyacrylamide-bonded capillary, where the relative migration time is the ratio of the migration time of SDS-protein to that of OG. High reproducibility in the migration time obviously resulted from the stabilization of the gel by suppression of 
Table 1 The run-to-run reproducibility of migration times and relative migration times on the $5 \% \mathrm{w} / \mathrm{v}$ linear polyacrylamide-bonded capillary

\begin{tabular}{lrrr}
\hline \multicolumn{1}{c}{ Sample } & MW & $\begin{array}{c}\text { Migration } \\
\text { time/min }\end{array}$ & $\begin{array}{c}\text { Relative } \\
\text { migration } \\
\text { time }\end{array}$ \\
\hline & & Mean \pm S.D. & Mean \pm S.D. \\
$\alpha$-Lactalbumin & 14400 & $5.65 \pm 0.05$ & $1.19 \pm 0.01$ \\
Trypsin inhibitor & 20100 & $6.05 \pm 0.06$ & $1.27 \pm 0.01$ \\
Carbonic anhydrase & 30000 & $6.72 \pm 0.07$ & $1.41 \pm 0.01$ \\
Ovalbumin & 43000 & $7.61 \pm 0.08$ & $1.60 \pm 0.01$ \\
Bovine serum albumin & 67000 & $8.91 \pm 0.09$ & $1.87 \pm 0.01$ \\
Phosphorylase $b$ & 94000 & $10.18 \pm 0.10$ & $2.14 \pm 0.02$ \\
$\beta$-Galactosidase & 116000 & $11.24 \pm 0.12$ & $2.36 \pm 0.02$ \\
\hline
\end{tabular}

Number of trials $(n=10)$. The separation conditions as in Fig. 2.

electroosmotic flow.

Table 2 lists the day-to-day reproducibility $(n=30)$ and the capillary-to-capillary reproducibility $(n=3)$ of migration times on the $5 \%$ linear polyacrylamide-bonded capillary. It is found that the developed capillary is sufficiently stable for repeated use and the capillary treatment method as described here is reasonably reproducible. The relative migration times listed in Table 1 and Table 2 indicate lower values for the relative standard deviations than those of migration times. This can be further improved by the precise control of the capillary temperature.

Figure 4 shows the relationship between electrophoretic mobility and $\log$ molecular weight of standard proteins measured on the capillaries at four different concentrations $(3,5,7$, and $9 \%)$ of linear polyacrylamide. Excellent linearity (correlation coefficient $r^{2}>0.998$ ) was obtained in each relationship. It is noted that the lines are roughly parallel to one another, as expected from size separation mechanism. ${ }^{17}$

Further validation of the size separation mechanism is confirmed by Fig. 5, which shows Ferguson plots ${ }^{18}$ of $\log$ mobility of individual SDS-protein versus concentration of linear polyacrylamide. As expected, all lines

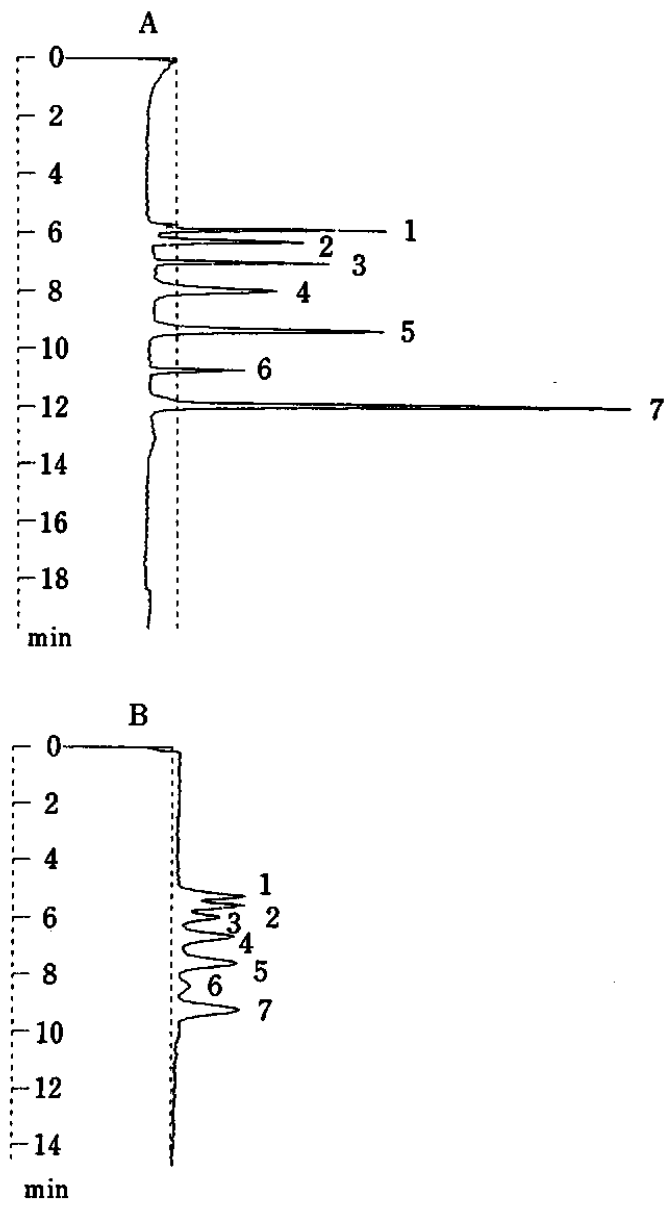

Fig. 3 Electropherograms of standard proteins on the SDSlinear polyacrylamide-filled capillary using the untreated fused silica capillary. Separation condition as in Fig. 2. (A) Ist run, (B) 5th run.

converged on the same mobility at $0 \%$, and the slopes of the seven lines are directly proportional to the molecular weight of the proteins. These results indicate that SDS was bound to proteins uniformly to yield constant charge density, and therefore the sieving is effected by the difference in size or molecular weight of the proteins.

Table 2 The day-to-day and the capillary-to-capillary reproducibility of migration times and relative migration times on the $5 \% \mathrm{w} / \mathrm{v}$ linear polyacrylamide-bonded capillary

\begin{tabular}{lccccc}
\hline \multirow{2}{*}{ Sample } & \multicolumn{2}{c}{ Day-to-day } & & \multicolumn{2}{c}{ Capillary-to-capillary } \\
\cline { 2 - 3 } \cline { 5 - 6 } & Migration time/min & Relative migration time & & Migration time/min & Relative migration time \\
\hline & Mean \pm S.D. & Mean \pm S.D. & & Mean \pm S.D. & Mean \pm S.D. \\
$\alpha$-Lactalbumin & $5.50 \pm 0.22$ & $1.18 \pm 0.01$ & & $5.80 \pm 0.19$ & $1.16 \pm 0.03$ \\
Trypsin inhibitor & $5.89 \pm 0.23$ & $1.27 \pm 0.01$ & & $6.25 \pm 0.21$ & $1.25 \pm 0.02$ \\
Carbonic anhydrase & $6.53 \pm 0.26$ & $1.40 \pm 0.01$ & & $6.91 \pm 0.24$ & $1.38 \pm 0.04$ \\
Ovalbumin & $7.38 \pm 0.31$ & $1.58 \pm 0.02$ & & $7.82 \pm 0.29$ & $1.57 \pm 0.04$ \\
Bovine serum albumin & $8.63 \pm 0.37$ & $1.85 \pm 0.02$ & & $9.14 \pm 0.36$ & $1.83 \pm 0.06$ \\
Phosphorylase $b$ & $9.84 \pm 0.42$ & $2.12 \pm 0.03$ & & $10.42 \pm 0.44$ & $2.09 \pm 0.07$ \\
$\beta$-Galactosidase & $10.88 \pm 0.48$ & $2.33 \pm 0.03$ & & $11.53 \pm 0.50$ & $2.31 \pm 0.08$ \\
\hline
\end{tabular}

Number of trials: day-to-day, $n=30$; capillary-to-capillary, $n=3$. The separation conditions as in Fig. 2. 


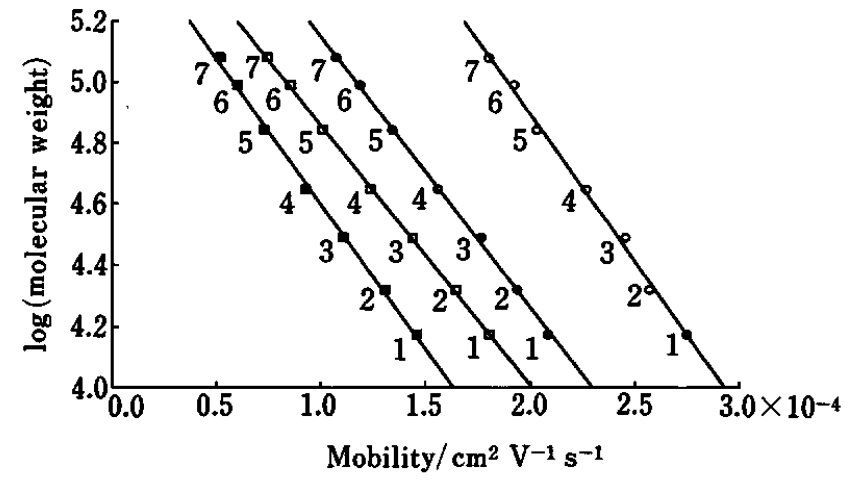

Fig. 4 Plots of $\log$ (molecular weight) of standard proteins as a function of mobility with the $3 \% \mathrm{w} / \mathrm{v}(\mathrm{O}), 5 \% \mathrm{w} / \mathrm{v}(0), 7 \% \mathrm{w} /$ $\mathrm{v}(\square)$ and $9 \% \mathrm{w} / \mathrm{v}(\square)$ polyacrylamide-bonded capillaries. The number specifies the proteins shown in Table 1.

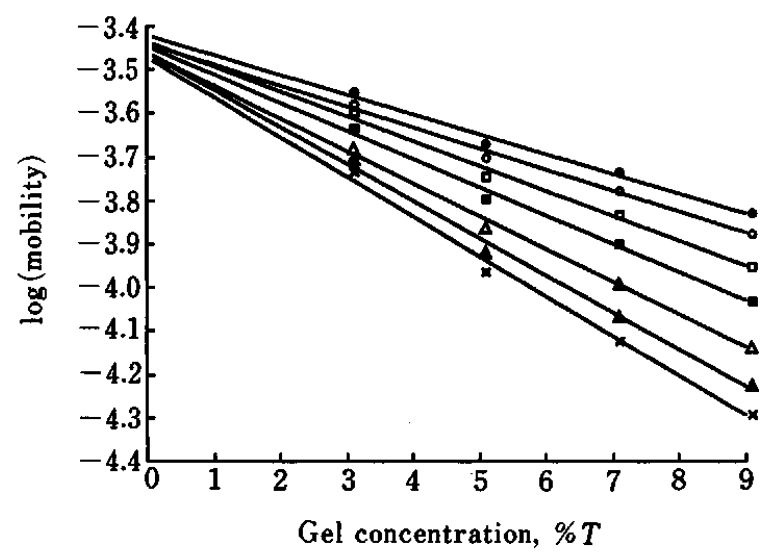

Fig. 5 Ferguson plots for linear polyacrylamide-bonded capillaries. $\alpha$-lactalbumin; $O$, trypsin inhibitor; $\square$, carbonic anhydrase; $\square$, ovalbumin; $\triangle$, bovine serum albumin; $\Delta$, phosphorylase $b ; \times, \beta$-galactosidase.

In conclusion, the covalent bondings of linear polyacrylamide to the inner wall of capillary through SiC linkages are hydrolytically stable. Thus, the good reproducibility is obtained and the life-span of the capillaries can be prolonged. The separation ability itself is almost the same as that of the coated capillary filled physically with the linear polyacrylamide solution which we reported previously. ${ }^{19}$ This indicates that the coatings of the inner wall of capillary are not always necessary, because the direct bondings of the sieving matrix deactivate silanol groups on the capillary surface.

\section{References}

1. K. Weber and M. Osborn, J. Biol. Chem., 244, 4406 (1969).

2. A. S. Cohen and B. L. Karger, J. Chromatogr., 397, 409 (1987).

3. K. Tsuji, J. Chromatogr., 550, 823 (1991).

4. A. Widhalm, C. Schwer, D. Blaas and E. Kenndler, $J$. Chromatogr., 549, 446 (1991).

5. D. Wu and F. E. Regnier, J. Chromatogr., 608, 349 (1992).

6. K. Ganzler, K. S. Greve, A. S. Cohen, B. L. Karger, A. Guttman and N. C. Cooke, Anal. Chem., 64, 2665 (1992).

7. A. Guttman, J. A. Nolan and N. Cooke, J. Chromatogr., 632, 171 (1993).

8. P. D. Grossman and J. C. Colburn, "Capillary Electrophoresis", p. 141, Academic Press Inc., San Diego, New York, Boston, London, Sydney, Tokyo, Toronto, 1992.

9. A. S. Cohen and B. L. Kager, J. Chromatogr., 397, 409 (1987).

10. A. S. Cohen, D. R. Najarian, A. Paulus, A. Guttman, J. A. Smith and B. L. Kager, Proc. Natl. Acad. Sci. U.S.A., 85, 9660 (1988).

11. P. F. Bente and J. Myertson, U. S. Patent 4810456 (1989).

12. H. F. Yin, J. A. Lux and G. Schomburg, J. High Resolut. Chromatogr., 13, 624 (1990).

13. V. Dolnik, K. A. Cobb and M. Novotny, J. Microcolumn Sep., 3, 155 (1991).

14. A. Guttman, A. S. Cohen, D. N. Heiger and B. L. Karger Anal. Chem., 62, 137 (1990).

15. K. K. Unger, "Porous Silica", Chap. 3, Elsevier Scientific Publishing Co., New York, 1979.

16. K. A. Cobb, V. Dolnik and M. Novotny, Anal. Chem., 62, 2478 (1990).

17. K. Weber and M. Osborn, J. Biol. Chem., 16, 4406 (1969).

18. K. A. Ferguson, Methabolism, 13, 1985 (1964).

19. M. Nakatani, A. Shibukawa and T. Nakagawa, Biol. Pharm. Bull., 16, 1185 (1993).

(Received August 10, 1993) (Accepted October 26, 1993) 